\title{
Comparison of Rank Transformation Test Statistics with Its Nonparametric Counterpart Using Real-Life Data
}

\author{
Adejumo T. Joel. ${ }^{1, *}$, Omonijo D. Ojo ${ }^{2,3}$, Owolabi A. Timothy ${ }^{1}$, Okegbade A. Ibukun ${ }^{1}$, \\ Odukoya A. Jonathan ${ }^{4}$, Ayedun C. Ayedun ${ }^{5}$ \\ ${ }^{1}$ Department of statistics, Ladoke Akintola University of Technology, Ogbomoso Oyo State, Nigeria \\ ${ }^{2}$ Department of Student Industrial Work Experience Scheme, Covenant University, Nigeria \\ ${ }^{3}$ Department of Sociology, Olabisi Onabanjo University, Ago-Iwoye, Nigeria \\ ${ }^{4}$ Department of Psychology, Covenant University, Ota, Nigeria \\ ${ }^{5}$ Department of Estate Management, Covenant University, Ota, Nigeria
}

Received August 4, 2020; Revised September 28, 2020; Accepted October 19, 2020

\section{Cite This Paper in the following Citation Styles}

(a): [1] Adejumo T. Joel., Omonijo D. Ojo, Owolabi A. Timothy, Okegbade A. Ibukun, Odukoya A. Jonathan, Ayedun C. Ayedun, "Comparison of Rank Transformation Test Statistics with Its Nonparametric Counterpart Using Real-Life Data," Mathematics and Statistics, Vol. 8, No. 6, pp. 683 - 692, 2020. DOI: 10.13189/ms.2020.080608.

(b): Adejumo T. Joel., Omonijo D. Ojo, Owolabi A. Timothy, Okegbade A. Ibukun, Odukoya A. Jonathan, Ayedun C. Ayedun (2020). Comparison of Rank Transformation Test Statistics with Its Nonparametric Counterpart Using Real-Life Data. Mathematics and Statistics, 8(6), 683 - 692. DOI: 10.13189/ms.2020.080608.

Copyright $\bigcirc 2020$ by authors, all rights reserved. Authors agree that this article remains permanently open access under the terms of the Creative Commons Attribution License 4.0 International License

\begin{abstract}
Over the years, non-parametric test statistics have been the only solution to solve data that do not follow a normal distribution. However, giving statistical interpretation used to be a great challenge to some researchers. Hence, to overcome these hurdles, another test statistics was proposed called Rank transformation test statistics so as to close the gap between parametric and non-parametric test statistics. The purpose of this study is to compare the conclusion statement of Rank transformation test statistics with its equivalent non parametric test statistics in both one and two samples problems using real-life data. In this study, (2018/2019) Post Unified Tertiary Matriculation Examinations (UTME) results of prospective students of Ladoke Akintola University of Technology (LAUTECH) Ogbomoso across all faculties of the institution were used for the analysis. The data were subjected to nonparametric test statistics which include; Asymptotic Wilcoxon sign test and Wilcoxon sum Rank (both Asymptotic and Distribution) using Statistical Packages for Social Sciences (SPSS). In the same vein, R-statistical programming codes were written for Rank Transformation test statistics. Their $\mathrm{P}$-values were extracted and compared with each other with respect to the pre-selected alpha level $(\alpha)=0.05$. Results in
\end{abstract}

both cases revealed that there is a significant difference in the median of the scores across all faculties since their type I error rate are less than the preselected alpha level 0.05 . Therefore, Rank transformation test statistics is recommended as alternative test statistics to non-parametric test in both one sample and two-sample problems.

Keywords Rank Transformation, Parametric, Non-parametric, Normal Distribution, Test Statistics

\section{Introduction}

In social, behavioural and physical sciences, studies have shown the usefulness of statistical analysis in arriving at conclusions in problems solving Odukoya, Omonijo, Olowookere, John \& Atayero, 2019; Olowookere, Omonijo, Odukoya \& Anyaegbunam, 2020). Also, in statistical analysis, non-normality of the data set may be inevitable, in case of the existence of such data set, the parametric test is not fit for the study. Hence, non-parametric tests or transformation of data becomes 
necessary or better still use a robust estimator to correct the anomalies.

However, Conover and Iman (1981) came up with another test statistic known as Rank transformation test statistics. Here all parametric test statistics were re-written in a rank form to fill the distance between parametric and non-parametric test statistics. Therefore, it is very imperative to apply some of these test statistics to real life data and compare whether the conclusion statement of rank transformation test statistics by Conover and Iman (1981) in one sample and two samples problems is the same with the already existing non-parametric test statistics. Hence, to accomplish this task the scores of post Unified Tertiary Matriculation Examination (Post-UTME) 2018/2019 academic session prospective students of Ladoke Akintola University of Technology (LAUTECH) across all faculties of the institution were collected and used for the analysis.

\section{Literature Review}

In order to find out how sensitive and robust some inferential statistics (one sample test statistics) are to outliers, Ayinde et al, (2016) carried out a simulation studies in this respect. Test statistics considered are student t-test, z-test, sign test, wilcoxon signed rank test (both distribution and asymptotic), rank transformation test and trimmed test statistics. In their study, the experiment was replicated five thousand times using montecarlo study and conducted at eight levels of sample sizes $\mathrm{n}=10,15,20,25,30,35,40$ and 50 . The data used in the study were simulated from Gaussian distribution with the aid of R-statistical programming codes. 10 and 20 percent of some randomly selected data were polluted with twenty-one magnitudes of outliers ranges from - 10 to +10 and compared the type I error rate of the test statistics with the most commonly used preselected alpha levels 0.1 , 0.05 and 0.01 . Their results revealed that the type I error rates of student t-test, Rank transformation test, Asymptotic wilcoxon test are good at all the preselected alpha levels. However, parametric tests were spotted to be sensitive to outliers. Also, at 0.1 level of significant; sign test distribution and its asymptotic, at 0.05 level of significant trimmed t-test, wilcoxon signed and at 0.01 level of significant; trimmed t-test and sign test asymptotic are robust to outliers respectively and thereby recommended.

In the same vein, Adegoke, et al. (2017) carried out a research on the sensitivity and robustness of matched pairs inferential test statistics to outliers. The inferential tests considered are Paired t-test, Distribution Wilcoxon Sign Test, Asymptotic Wilcoxon Sign Test, Distribution and Asymptotic Wilcoxon Signed rank Test, Rank transformation test and Trimmed t-test statistics. The experiment was conducted five thousand (5000) times using Monte Carlo experiments at eight (8) levels of sample sizes namely: 10, 15, 20, 25, 30, 35, 40 and 50 whereby data were simulated from Gaussian distribution with the aid of R- statistical programming codes. Also, to exhibit a different degree of correlations between the paired samples, the levels of correlations reconsidered are; $0,0.3,0.6,0.9,0.95$, and 0.99 . At each sample size, ten and twenty percent of the simulated data were invoked with twenty-one (21) various magnitude $(\mathrm{k})$ of outliers ranges from -10 to +10 . The three (3) commonly used preselected levels of significance used were $0.1,0.05$, and 0.01 . The Type I error rate of the inferential test statistics was determined when there was no outlier in the data sets. While to assess the sensitivity and robustness of the test statistics hence, Power rate was determined. Also, in their study, they affirmed that a test was examined to be robust if its estimated type I error rate approximately equal to the true error rate and it has the highest number of times it approximates the error rate when counted over the preselected alpha level otherwise sensitive. Their results revealed that paired t-test and Asymptotic wilcoxon sign test have better Type I error rate across different categories of correlation and that Asymptotic sign test, Rank transformation test and distribution sign test, and Trimmed t-test statistics are respectively robust to outliers at all alpha levels.

As a means for understanding the nature of rank transform, this made Michael (1990) to make use of rank transform asymptotic version of it for testing problems in some two factor designs. In his investigation, he found out that this version works well and helps to suggest which Analysis of Variance (ANOVA) procedure should be employed. He applied this method on the balanced and unbalanced nested model including their two way layout with and without interaction.

Attention was paid to Aligned Rank Transform (ART) by Mausouri, et al (2007). They considered ART as a testing procedure in linear model where two way layout and multiple comparison techniques were considered. The authenticity of the technique was ascertained through simulation study and results revealed that the technique procedure was found to be quiet robust against violations of the assumption of continuous error distribution. Edgar and Holger (2012) explicitly form a test statistic which was derived with the aid of partial rank transform and its asymptotic distribution was also determined. Their research was centered on the two factor mixed models (Rank procedures) where fixed treatment effects as a problem was considered in two factors, mixed model with interaction and unequal cell frequencies in the absence of normality assumptions. Their further research revealed that when cell frequencies are not equal, they regarded generalization of Friedman's test as a proposed test statistic. In their research, they compared the proposed test with the equivalent already existing test under the assumption of normality by the criterion of asymptotic 
relative efficiency. Finally, the exact condition distribution was discovered and proposed are the estimators and confidence intervals for the shift effect.

An investigation was carried out by Haiko (2017) on the implication of discrete distribution on the error rates. The analysis was centered on the two-way layouts Analysis of Variance (ANOVA) design, the Aligned Rank Transform (ART) and compared it with the parametric F-test. Also, some other nonparametric tests considered are; Rank Transform, Inverse Normal Transform, combination of ART and INT, combination Puri and Sen's L statistics, Van der Waerden and Akritas and Brunners ATS. In the same vein, two major continuous distributions were used which include; Uniform and exponential distributions. He restricted his scaling impact to ART and the combination of ART and INT methods. In his analysis, two effects were revealed; first one with increasing cell counts where their error rates rise beyond any acceptable limit up to 20 percent and more. Likewise, the error rates of the second one rise as the number of the dependent variables decrease. But for underlying exponential distribution, its behavior is distinctively severe than that of uniform distribution. He finally claimed that if the mean cell frequencies are more than ten (10) ART should not be applied.

A most powerful sequential rank test was derived in (2017) by Jan. the test was meant for the hypothesis of randomness against a general alternative which include as a special case for the alternative hypothesis regression in location or the two samples difference in location. As the classical results of Hajek and Sidak (1967), he also derived for the one sample problem for independence of two samples in an analogous spirit. For a fixed sample size similarly, he derived its test and the results obtained brought about argument in favour of already existing ones.

Rayner and Best (2013) did a thorough work on rank transformation and Analysis of variance by extending the procedures of rank transformation for balanced designs. Their research was centered on the construction of table of counts for the mid - ranks of data where they made use of contingency table constructed by Beh and Davy (1998, 1999) so as to partition the test statistic of Pearson.

Furthermore, in the further application of rank transformation, Mitchell et al, (1994) compared and contrasted the results of rank transformation test statistic with parametric test when applied to genotoxicity data with examples from cultured Mammalian cells. In their study, the results of rank transformation test revealed that there was no loss of power and compete favourably with parametric test. Likewise, when there is $2 \times 2 \times 2$ fixed effects Analysis of Variance, Sawilowsky et al, (1989) investigated the power and type I error rates of the rank transformation statistic. Their research showcased that in some situation, rank transformation was declared robust and not robust at times under some certain circumstances.
In order to determine the efficacy and efficiency of rank transformation test relative to $\mathrm{F}$ - test, Thompson and Ammann (1989) carried out a research in this direction. They concluded that the efficacy of rank transformation coincides with the Kruskal - Wallis test. Also, in (1999) Thompson embarked on an in-depth study on rank transform statistic proposed by Conover and Iman (1981) which was based on testing for interaction in a balanced two - way classification. He was able to find out that rank transformation is asymptotically chi - squared divided by its degrees of freedom even when there is only one main effect and exactly two levels of both main effect. He further corroborated that as the sample size is increasing, the expected value of the rank transformation is tending to infinity.

\subsection{Non-parametric}

The alternative test to parametric tests when the distribution from which data are collected are indisposed is the non-parametric test. Non-parametric test has being in existence as early as the 13th century or earlier use in estimation by Edward Wright, 1599. John Arbuthnot, (1710) in his early analysis used non-parametric statistics which include the median and the sign test in analyzing the human sex ratio at birth.

Moreover, nonparametric tests are usually used to test the hypothesis that has nothing to do with population parameters but rather based on the shape of the population frequency distributions. It is generally known that, if the data do not satisfy the properties of parametric test (that is normality assumptions, equal variance, and continuous), then such data may be analyzed with a nonparametric test. But in a real sense, if a nonparametric test is required, additional data may be needed to make the same general conclusion. (Ayinde, et al, 2016).

\subsubsection{Characteristics of nonparametric}

The non-parametric test has some characteristics which are highlighted as follows:

(i) Populations from which samples are taken arefewer and weaker.

(ii) Interval scale of measurements is not required.

(iii) It usually based on medians.

(iv) Measurements are reduced to ranks or signs.

\subsubsection{Advantages of Non-parametric statistics}

(i) Nonparametric statistics does not need rigid parametric assumptions with regards to the population from which the observations are taken.

(ii) nonparametric statistics are usually wider in scope since there are little assumptions about the sample being considered.

(iii) Population parameters are not involved in nonparametric tests.

(iv) Since most nonparametric procedures depend on a minimum set of assumptions hence, their chance of being properly used are small. 
(v) It is usually useful when data is nominal or ordinal even when measured on a weak measurement scale.

(vi) The procedure is very easy to understand even for the researchers who are not mathematically or statistically oriented.

(vii) Its Computations are easy to perform even without automated instrument such as calculators or computers compared to parametric test.

(viii) They are meant for small numbers of data, such as; classifications, counts, and ratings.

\subsubsection{Disadvantages of Non-parametric tests}

Nonparametric procedures are not without disadvantages. The following are some of the more important disadvantages.

(i) May Waste Information. The researcher may waste information when parametric procedures are more appropriate to use.

(ii) If sample size is large, data manipulations tend to become more tedious unless computer software are used.

(iii) Tables not widely available. Unlike parametric test that its critical values are readily available in statistical table. Unique tables are needed for critical values.

Table 1 displays aim of one sample nonparametric tests

Table 1. The table of Non-parametric and its aim

\begin{tabular}{cc}
\hline Non-Parametric Test & Aim of test \\
Wilcoxon signed rank test. & to compare two dependent \\
Mann-Whitney U-test. & samples. \\
Wilcoxon rank sum test & to compare two independent \\
\hline
\end{tabular}

Source: Jagoo, G. (2012)

\subsubsection{General steps to carry out a Non-Parametric Test}

(i) The null hypothesis and the alternative hypothesis are stated.

(ii) The significance level, related with the null hypothesis is normally set at $5 \%$ and therefore the confidence level is $95 \%$.

(iii) The suitable statistic test is chosen. This is done by taking into account: the number of samples, that is whether the samples taken are dependent or independent and also the type of data.

(iv) The test statistic is then calculated. For small sample, a method particular to a specific statistical test is used. Then, for large samples, the data is approximated to a normal distribution and the $\mathrm{z}$-score is evaluated.

(v) The value required to reject the null hypothesis is determined using the suitable table for critical values for the specific statistic

(vi) The obtained value is compared with the critical value. This enables us to find the difference based on a specific significance level. Then, we can assert whether the null hypothesis should be rejected or not. (vii) The results are explained and a conclusion is drawn out. (Hesse et al, 2018).

\subsection{One Sample Test}

\subsubsection{The sign test}

One sample parametric test that is used to compare a single sample with some hypothesized value is called the sign test. The sign test is being used in a situation whereby one sample or paired t-test is majorly applied. To each observation it assigns a sign either positive or negative according to whether it is greater or less than some hypothesized median value and considers whether this is substantially different from what we would expect by chance. If any observation is exactly equal to the hypothesized median they are ignored and dropped from the sample size. The test statistics are $t^{+}$or $t^{-}$as the case may be. If values with negative signs are the least, then our test statistic is $t^{-}$, otherwise the test statistic is $t^{+}$. if $\mathrm{P}\left(\mathrm{t} \leq t^{+}\right)<\alpha$ or $\mathrm{P}\left(\mathrm{t} \leq t^{-}\right)<\alpha$ Under null hypothesis, binomial distribution is used and null hypothesis is hereby rejected. When the test is two-tail, $\alpha / 2$ is used instead of $\alpha$. The sign test has its distribution following binomial ( $\mathrm{n}, 1 / 2$ ) asymptotically. (Ayinde, et al, 2016).

\subsubsection{The asymptotic test}

The asymptotic test statistic for sign test is

$$
Z=\frac{t^{+}-\frac{n}{2}}{\sqrt{\frac{n}{4}}} \sim \mathrm{N}(0,1)
$$

\section{Procedures:}

To run a sign test, the following assumptions must hold:

(i) Observations must be measured on at least ordinal scale.

(ii) The sample must be randomly drawn from the population.

(iii) The probability of values falling on the hypothesized median is low.

\subsection{Two Samples Test}

\subsubsection{Wilcoxon rank sum test}

This is a test that is quick and easy for two independent samples. It is a good alternative test to the student t-test when the normality assumptions about the data could not hold. The numerical alternative test to it is Mann-Whitney U-test. If only ordinal data are available the test can also be performed. With respect to the median, it tests the null hypothesis that the two distributions are identical against the alternative hypothesis that the two distributions differ. 
The test is based on the Wilcoxon rank sum test statistic "W', which is the sum of the ranks of one of the samples.

\subsubsection{Wilcoxon rank sum test assumptions:}

(i) The observations are independently and identically distributed within each samples.

(ii) The two samples are independent of each other.

(iii) The error terms are mutually independent.

(iv) The spreads and shapes of the distributions are the same.

\section{The procedures:}

(i) All data are ranked from smallest up to the largest.

(ii) Add the ranks in the smaller group to get the test statistic $\mathrm{W}$, if one group has fewer values than the other such as $\mathrm{n}_{1}<\mathrm{n}_{2}$ and if $\mathrm{n}_{1}=\mathrm{n}_{2}$, add the ranks in the group containing the most smallest ranks.

(iii) Check the appropriate table for the statistic $\mathrm{W}$ based on the sample sizes and determine its probability accordingly.

(iv) Reject $\mathrm{H}_{0}$ or accept $\mathrm{H}_{0}$ based on the p-value, the statistic $\mathrm{W}$ becomes approximately normal as the two sample sizes increase.

By standardizing $\mathrm{W}$ the test $\mathrm{Z}$-statistic is given as;

$$
\mathrm{Z}=\frac{W-\mu_{w}}{\sigma_{w}} \sim N(0,1)
$$

Where,

$$
\begin{gathered}
\mu_{w}=\frac{n_{1}(N+1)}{2}, \\
\sigma_{w}=\sqrt{\frac{n_{1} n_{2}(N+1)}{12} \text { and } N=n^{1}+n^{2} .}
\end{gathered}
$$

When the null hypothesis (no difference in distributions) is true, P-values for the Wilcoxon test are based on the sampling distribution of the rank sum statistic W. Also, from special tables, software or a normal approximation (with continuity correction)P-value can be calculated.

\subsection{Rank Transformation}

According to Conover and Iman, (1981) they defined Rank Transformation as one in which the parametric procedure is applied to the ranks of the data instead of the data themselves. They developed some parametric tests in their rank form which was considered as a viable tool for developing new non-parametric procedures to solve new problems. Non-parametric methods as an integral part of an introductory course in statistics this new approach provides a useful pedagogical technique.

Also in a situation where parametric assumptions could not hold, this approach is viewed as a useful tool for developing new non-parametric methods. (Conover and Iman, 1981 and Ayinde, et al, (2016)).

\subsubsection{T-test for Rank Transformation in one sample}

Let $D_{1}, D_{2}, \ldots, D_{n}$ be independent random variables with the same mean but in the case of matched pairs $\left(\mathrm{X}_{\mathrm{i}}\right.$, $\left.\mathrm{Y}_{\mathrm{i}}\right) ; \mathrm{D}_{\mathrm{i}}=\mathrm{X}_{\mathrm{i}},-\mathrm{Y}_{\mathrm{i}}$. For the case of one sample $\mathrm{D}_{\mathrm{i}}=\mathrm{X}_{\mathrm{i}}-\mu_{0}$ where $\mu_{0}$ is the hypothesized mean value. For the Wilcoxon signed rank test the $\mathrm{D}_{\mathrm{i}}$ 's are replaced by the signed ranks $R_{i}$, where $R_{i}=\left(\operatorname{sign} D_{i}\right) \times\left(\right.$ rank of $\left./ D_{i} /\right)$.

$$
T=\frac{\sum_{l=1}^{n} R_{i}}{\sqrt{\sum_{l=1}^{n} R_{i}^{2}}}
$$

When the test statistic $\mathrm{T}$ is too large or too small as measured by the normal approximation, the hypothesis is hereby rejected.

Alternatively t-test statistic is computed on the signed ranks as follows;

$$
t_{R}=\frac{\sum_{l=1}^{n} R_{i}}{\sqrt{\frac{n \sum_{l=1}^{n} R_{i}^{2}-\left(\sum_{l=1}^{n} R_{i}\right)^{2}}{n-1}}}
$$

This is compared with the t-distribution (n-1) df (degree of freedom).

\subsubsection{T-test for Rank Transformation in two independent samples}

Assuming that $X_{1},------X_{n}$ and $Y_{1,-------} Y_{n}$ are two independent random samples. To test the hypothesis that $\mu_{1}=\mu_{2}$ the parametric procedure employs the two sample t-statistic.

$$
\mathrm{t}=\frac{\left(\bar{X}_{1}-\bar{Y}_{2}\right)-\left(\mu_{1}-\mu_{2}\right)}{\sqrt{S \sqrt{ }(1 / n 1)+(1 / n 2)}}
$$

where $S=\frac{\left(n_{1}-1\right) S_{1}^{2}+\left(n_{2}-1\right) S_{2}^{2}}{n_{1}+n_{2}-2}$ compares with $n_{1}+n_{2}-$ 2 degree of freedom.

The non-parametric Wilcoxon Mann-Whitney twosamples test requires by replacing the data by the ranks $R_{i}$ from 1 to $\mathrm{N}$, and uses the statistic in its standard form with the adjustment for ties incorporated.

$$
\text { Thus, } T=\frac{S-\frac{n(N+1)}{2}}{\sqrt{\frac{n_{1} n_{2} \sum_{i=1}^{N} R_{i}^{2}}{N(N-1)}-\frac{n_{1} n_{2}(N+1)^{2}}{4(N-1)}}}
$$

Where $N=n_{1}+n_{2}-2$ and $\mathrm{S}=\sum_{i=1}^{n} R_{i}$ is denoted to be the sum of ranks of the independent variables (X's). The statistic is compared with the standard normal distribution and exact tables may be used for $\mathrm{S}$ if there are no ties and the sample sizes are less than 20. (Conover, 1980).

Its procedure is based by computing $t$ on the rank of $R_{i}$ 
to get the statistic given in equation (7).

$$
t R=\frac{\frac{S}{n_{1}}-\frac{1}{n_{2}}\left(\frac{N(N+1)}{2}-S\right)}{\sqrt{\left[\left(\sum_{i=1}^{N} R_{i}^{2}-\frac{S^{2}}{n_{1}}-\frac{1}{n_{2}}\left(\frac{N(N+1)}{2}-S\right)^{2}\right) \frac{N}{n_{1} n_{2(N-2)}}\right]}}
$$

With $n_{1}+n_{2}-2$ degree of freedom.

According to Conover and Iman (1981), algebraically an important relationship between $\mathrm{tR}$ and $\mathrm{T}$ is revealed as:

$$
t R=\frac{T}{\sqrt{\frac{N-1}{N-2}-\frac{T^{2}}{N-2}}}
$$

by mathematical expression, $\mathrm{tR}$ is a monotonically increasing function of $\mathrm{T}$.

Therefore, with all of Wilcoxon - Mann -Whitney test good properties, it may be performed using tR as a test statistic instead of T. (Conover and Iman, 1981)

\section{Data Analysis}

\subsection{Descriptive Analysis}

The descriptive analysis of results of (2018/2019) Post UTME of Ladoke Akintola University of Technology (LAUTECH) prospective students across all faculties of the institution was carried out using SPSS. The following results were obtained as seen in table 2 :
Table 2. The frequency table of all the applicants with respect to their intending faculty

\begin{tabular}{ccccc}
\hline Faculty & Frequency & Percent & $\begin{array}{c}\text { Valid } \\
\text { Percent }\end{array}$ & $\begin{array}{c}\text { Cumulative } \\
\text { Percent }\end{array}$ \\
\hline $\begin{array}{c}\text { Basic Medical } \\
\text { Science } \\
\text { Engineering } \\
\text { and Tech } \\
\text { Pure and } \\
\text { Applied }\end{array}$ & 3772 & 57.6 & 57.6 & 57.6 \\
$\begin{array}{c}\text { Science } \\
\text { Agricultural } \\
\text { Science }\end{array}$ & 1522 & 23.2 & 23.2 & 80.8 \\
$\begin{array}{c}\text { Environmental } \\
\text { Science }\end{array}$ & 347 & 9.6 & 9.6 & 90.5 \\
$\begin{array}{c}\text { Management } \\
\text { Science } \\
\text { Total }\end{array}$ & 72 & 3.1 & 3.1 & 98.9 \\
\hline
\end{tabular}

Source: Computer output

Comment: Across all faculties, 6548 candidates applied, 3772 applied to study under the faculty of Basic medical Science, 1522 applied to study under Engineering and technology, 631 applied to study under Pure and applied science, 347 applied to study under Agricultural science, 204 applied to study under Environmental science while 72 applied to study under Management science.

The Bar chat for the frequency distribution table is shown (see figure 1) and table 2 respectively, indicating the faculty of Basic Medical science as the highest faculty applied for by the applicant and Management science as the least faculty applied for by the applicant. 


\section{Test of Normality across all faculties}

\section{Hypothesis test}

$\mathrm{H}_{0}$ : The applicant score are normally distributed

$\mathrm{H}_{1}$ : The applicant score are not normally distributed

Table 3. Test of Normality across all faculties

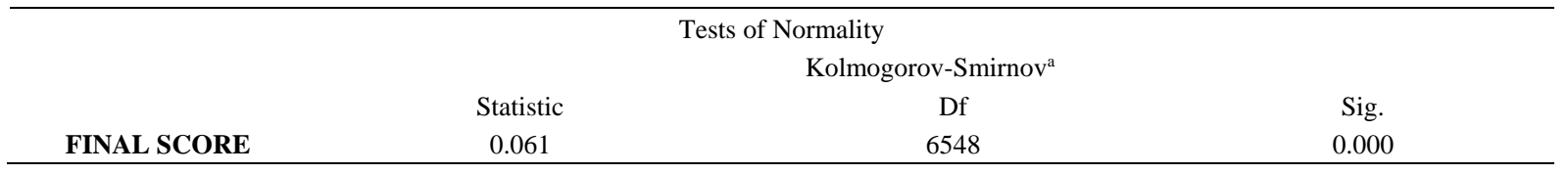

Kolmogorov-Smirnov $=0.061, \mathrm{p}$-value $=0.00$

\section{FACULTY}

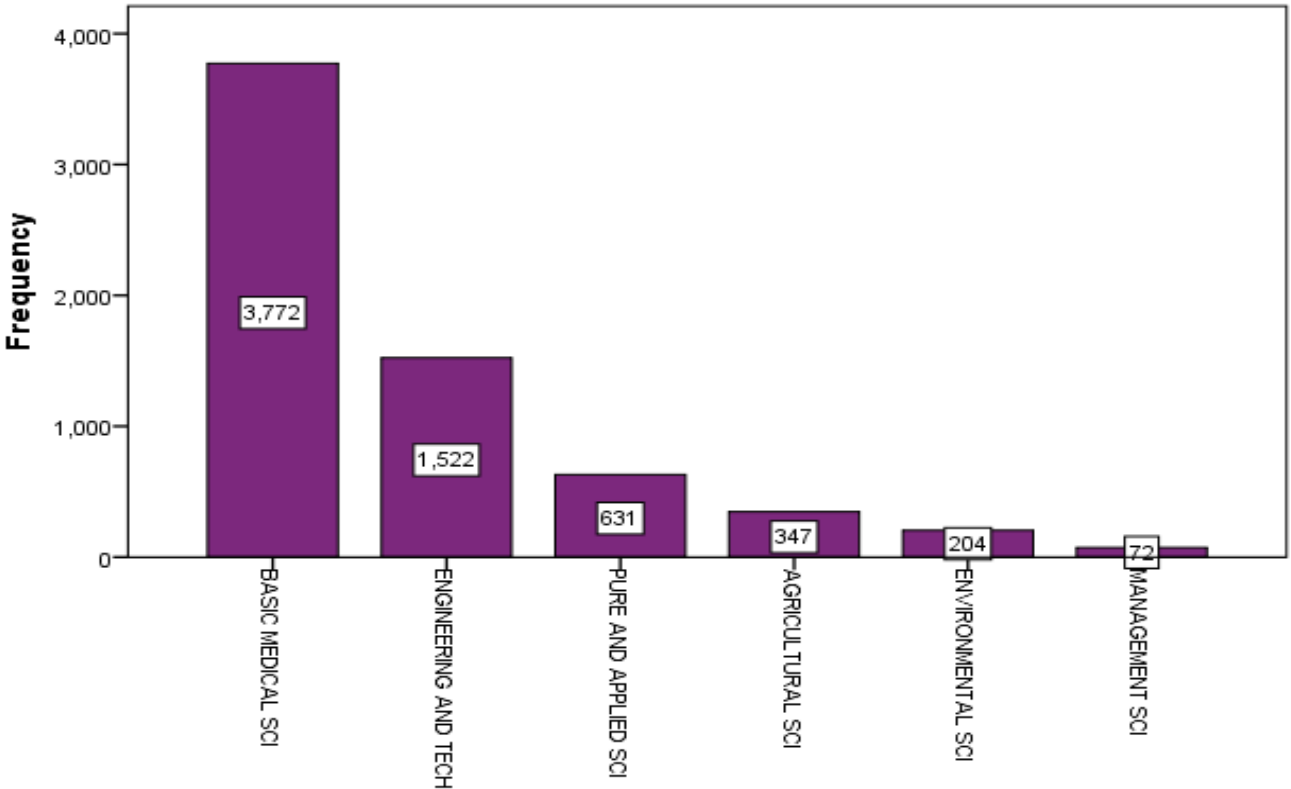

Figure 1. Showing Barchat of the faculty frequency

\section{Histogram}

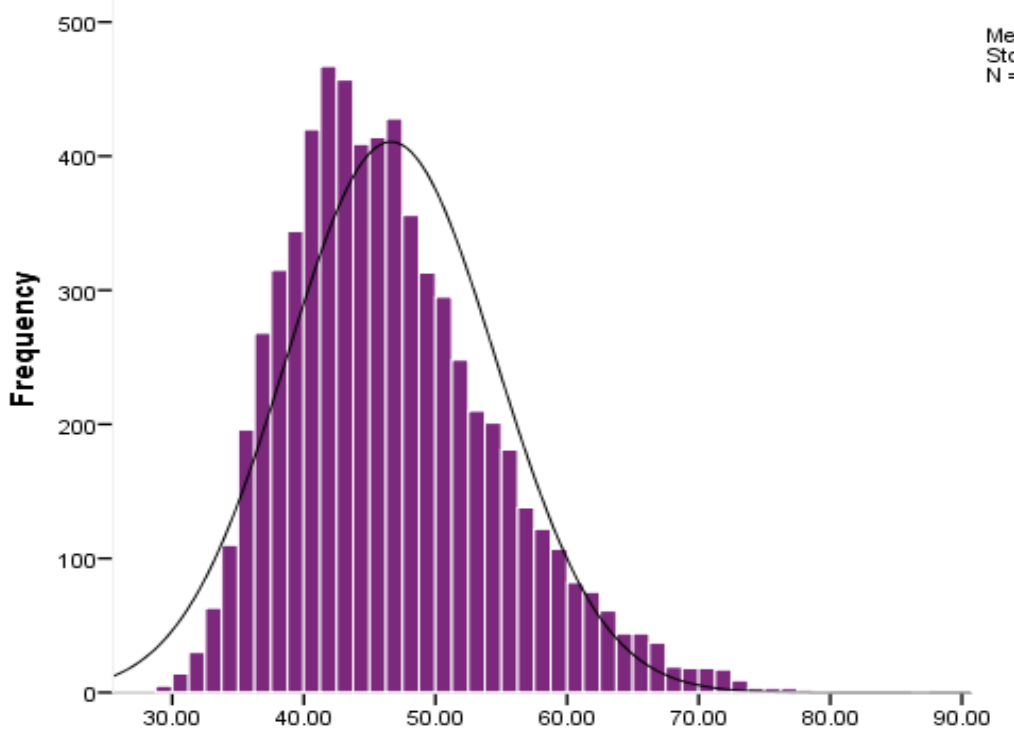

Figure 2. Showing the Normality Distribution curve for all faculties

Comment: From table 3 and figure 2, it can be seen that the data are not normally distributed for all faculties since the p-value $(0.000)<\alpha(0.05)$. 


\subsection{One Sample Problem}

$\mathrm{H}_{0}$ : The median score is not significantly different

$\mathrm{H}_{1}$ : The median score is significantly different

Table 4. Table of results for Sign test and Rank transformation

\begin{tabular}{ccc}
\hline FACULTY & NONPARAMETRIC & $\begin{array}{c}\text { RANK TRANSFORMATION } \\
\text { TEST STATISTICS }\end{array}$ \\
\hline & Wilcoxon sign test (Asymptotic) & $\begin{array}{c}\text { Rank Transformation in one } \\
\text { sample problem }\end{array}$ \\
\hline PURE AND APPLIED SCIENCE & 0.968245 & 0.247092 \\
AGRICULTURAL SCIENCE & 0.788381 & 0.356228 \\
BASIC MEDICAL SCIENCE & 0.939999 & 0.358016 \\
ENVIRONMENTAL SCIENCE & 1.000000 & 0.380740 \\
MANAGEMENT SCIENCE & 0.813664 & 0.435918 \\
ENGINEERING AND TECH & 0.969914 & 0.118874 \\
\hline
\end{tabular}

Source: Computer output

Comment: Table 4 shows that there is no significant difference in the median scores across all faculties in both test statistics since their P-values are greater than the preselected alpha level 0.05 . Therefore, rank transformation can also be used as an alternative test statistic to a non-parametric test statistics in one sample problem.

\subsection{Two Samples Problem}

$\mathrm{H}_{0}$ : There is no significant difference between the medians of the two groups

$\mathrm{H}_{1}$ : There is a significant difference between the medians of the two groups.

Table 5. Table of results for Wilcoxon rank-sum test and rank transformation

\begin{tabular}{|c|c|c|c|}
\hline \multirow[t]{3}{*}{ FACULTY } & \multicolumn{2}{|c|}{ NON-PARAMETRIC } & \multirow{3}{*}{$\begin{array}{c}\text { RANK TRANSFORMATION } \\
\text { Rank transformation in two } \\
\text { samples problem } \\
\end{array}$} \\
\hline & \multicolumn{2}{|c|}{ Wilcoxon Sum Rank } & \\
\hline & Distribution & Asymptotic & \\
\hline $\begin{array}{l}\text { PURE AND APPLIED SCIENCES AND AGRICULTURAL } \\
\text { SCIENCES }\end{array}$ & 0.000301 & $6.17 \mathrm{E}-148$ & $2.97 \mathrm{E}-248$ \\
\hline $\begin{array}{l}\text { PURE AND APPLIED SCIENCES AND } \\
\text { ENVIRONMENTAL SCIENCES }\end{array}$ & 0.000585 & $1.01 \mathrm{E}-78$ & $2.52 \mathrm{E}-53$ \\
\hline $\begin{array}{l}\text { PURE AND APPLIED SCIENCES AND ENGINEERING } \\
\text { TECH }\end{array}$ & 0.036967 & 0 & $1.25 \mathrm{E}-147$ \\
\hline $\begin{array}{l}\text { PURE AND APPLIED SCIENCES AND BASIC MEDICAL } \\
\text { SCIENCES }\end{array}$ & $1.40 \mathrm{E}-06$ & 0 & $1.32 \mathrm{E}-147$ \\
\hline $\begin{array}{l}\text { PURE AND APPLIED SCIENCES AND MANAGEMENT } \\
\text { SCIENCES }\end{array}$ & 0.000585 & $3.91 \mathrm{E}-25$ & $2.52 \mathrm{E}-53$ \\
\hline $\begin{array}{l}\text { BASIC MEDICAL SCIENCES AND ENVIRONMENTAL } \\
\text { SCIENCES }\end{array}$ & $1.40 \mathrm{E}-06$ & $3.75 \mathrm{E}-105$ & $8.17 \mathrm{E}-63$ \\
\hline $\begin{array}{c}\text { BASIC MEDICAL SCIENCES AND ENGINEERING AND } \\
\text { TECH }\end{array}$ & 0.000297 & $1.21 \mathrm{E}-231$ & 0 \\
\hline $\begin{array}{l}\text { BASIC MEDICAL SCIENCES AND AGRICULTURAL } \\
\text { SCIENCES }\end{array}$ & $1.40 \mathrm{E}-06$ & $3.75 \mathrm{E}-105$ & $6.93 \mathrm{E}-51$ \\
\hline $\begin{array}{l}\text { MANAGEMENT SCIENCES AND ENGINEERING AND } \\
\text { TECH }\end{array}$ & $1.64 \mathrm{E}-06$ & 0 & $6.82 \mathrm{E}-51$ \\
\hline $\begin{array}{l}\text { MANAGEMENT SCIENCES AND AGRICULTURAL } \\
\text { SCIENCES }\end{array}$ & 0.000585 & $1.01 \mathrm{E}-78$ & $6.82 \mathrm{E}-51$ \\
\hline $\begin{array}{l}\text { MANAGEMENT SCIENCES AND BASIC MEDICAL } \\
\text { SCIENCES }\end{array}$ & $3.77 \mathrm{E}-11$ & 0 & $6.93 \mathrm{E}-51$ \\
\hline $\begin{array}{l}\text { ENGINEERING AND TECH AND AGRICULTURAL } \\
\text { SCIENCES }\end{array}$ & $9.52 \mathrm{E}-228$ & $9.52 \mathrm{E}-228$ & 0 \\
\hline $\begin{array}{l}\text { MANAGEMENT SCIENCES AND ENVIRONMENTAL } \\
\text { SCIENCES }\end{array}$ & 0.000585 & $1.01 \mathrm{E}-78$ & $2.52 \mathrm{E}-53$ \\
\hline $\begin{array}{l}\text { ENGINEERING AND TECH AND ENVIRONMENTAL } \\
\text { SCIENCES }\end{array}$ & 0.036967 & $4.71 \mathrm{E}-105$ & $1.25 \mathrm{E}-147$ \\
\hline
\end{tabular}

Source: Computer Output

Comment: From table 5, it can be seen that there is a significant difference between the medians of the two groups (faculties) in both test statistics since their type I error rate is less than the preselected alpha level 0.05. Thus, rank transformation can also be used as an alternative test statistic to non-parametric test statistics in two samples problem. 


\section{Conclusions}

The data used in the analysis for each faculty are described using descriptive analysis which shows that faculty of Basic Medical sciences has the highest number of applicants with 3772 number of applicants, faculty of Engineering and Technology was the second with 1522 number of applicants, faculty of pure and applied science was the third with 631 number of applicants, faculty of Agricultural Science was the fourth with 347 number of applicants, faculty of Environmental science was the fifth with 204 number of applicants and faculty of Management science has the least applicants with a total number of 72 applicants.

The test of normality was carried out on applicant post UTME score for each faculty using Shapiro-wilk test for the data and it was discovered that the score is not normally distributed across all faculties and thereby shows that parametric test is not suitable for the analysis.

The data were subjected to Non-parametric tests using Wilcoxon asymptotic sign test, Wilcoxon sum rank (Asymptotic and distribution), and rank transformation test statistics in one and two sample problems.

The results of the analysis show that all scores for each faculty is not normally distributed.

Also, sequel to the outcome of the results in both nonparametric and Rank transformation test statistics in one sample problem, there is no significant difference in the median score since their type I error rates is greater than the preselected alpha level 0.05. Also, in two sample problems, there is a significant difference between the medians of the two groups (faculties) in both test statistics since their type I error rate is less than the preselected alpha level 0.05 .

Consequently, Rank transformation test statistics can be used as an alternative hypothesis testingto the nonparametric test when normality assumptions are violated in the data set.

\section{Acknowledgments}

We acknowledge the financial support for this paper from the Covenant University Centre for Research and Innovation Development (CUCRID). Our appreciation also goes to the Director of Information and Communication Technology (ICT) Ladoke Akintola University of Technology (LAUTECH) Ogbomoso, in person of Dr. (Mrs.) Baale for her indelible efforts she made in releasing the data used for analysis in this study. Finally, the efforts of the Ag. Head of the department of statistics Dr. D. B. Adekanmbi is highly appreciated for her all-round support in making this research work a success.

\section{REFERENCES}

[1] Adegoke, S. A., Adejumo,T. J. and Ayinde, K. (2017). A study on Sensitivity and Robustness of matched- pairs test statistics to outliers. FUTA J. Res. Sci., Vol. 13 (2), October, 2017:350 -363.

[2] Ayinde, K.., Adejumo, T. J. and Solomon, S. G. (2016). A study on Sensitivity and Robustness of one sample test Statistics to outliers. Global Journal of Science Frontier Research (GJSFR). Vol. 16(6); 99-112 Dec; 2016.

[3] Beh, E. J. and Davy, P. J. (1998). Partitioning Pearson's Chi - squared statistic for a completely ordered three way contingency table. Aust. N. Z. J. stat. 40, 465- 477.

[4] Beh, E. J. and Davy, P. J. (1999). Partitioning Pearson's Chi - squared statistic for a partially ordered three way contingency table. Aust. N. Z. J. stat. 41, $233-246$.

[5] Conover, W. J. and Iman, R. L. (1981). Rank transformations as a bridge between parametric and nonparametric statistics. The American Statisticians, Volume 35, 125 - 129.

[6] Edgar, B. and Holger, D. (2012). Rank Procedures for the Two - Factor Mixed Model. Journal of theAmerican Statistical Association. Volume 87, Issue 419, 884 - 888.

[7] Haiko, L. (2017). The aligned rank transform and discrete variables: A warning. Communication in statistics-simulati on and computation. Volume 46, issue 9, 6923-6936.

[8] Hesse, C.A., Ofosu, J.B., and Nortey V. E (2012). Introduction to non-parametric statistics method Vol. 1, Pg. 4-6.

[9] Jagoo G. (2018). Non-parametric Test, Vol. 1, pg. 10.

[10] Jan, K. (2017). On locally most powerful sequential rank tests. Journal of sequential Analysis - Design methods and Applications. Volume 36, issue (1), 111- 125.

[11] John, A. (1710). Sign test- the free encyclopedia, <http://www.encyclopedia.com.2016.

[12] Ladoke Akintola University of Technology: <www.lautech. edu.ng. 2019.

[13] Mansouri, H., Paige, R. L. and Surles, J. G. (2007) Aligned Rank Transform Techniques for Analysis of Variance and Multiple. Communication in statistics- Theory and methods. Volume 46, 2217-2232.

[14] Mitchell, G., Amphlett, N. W. and Rees, R. W. (1994). Parametric analysis of rank transformed data for statistical assessment of genotoxicity data with examples from cultured Mammalian cells. Mutagenesis, vol.9 (2). Pp. 125 132. Doi: 10.1093/mutage/9.2.125.

[15] Michael, G. A. (1990). The Rank Transform Method in Some Two - Factor Designs. Journal of the American Statistical Association.Vol. 85, No. 409, pp. $73-78$.

[16] Olowookere, E. I; Omonijo, D. O; Odukoya, J. A and Anyaegbunam, M. C., (2020). Exploring the Effect of Gender and Personality Characteristics on Educational Performance. Journal of Educational and Social Research, 10(5): 99-107. https://doi.org/10.36941/jesr-2020-0091

[17] Odukoya. J. A. Omonijo D. O., Olowookere, E. I., John, M 
and Atayero, A.A.A. (2019). Age Admission Policy in Universities: In Search of Empirical Evidence. International Journal of Scientific and Technology Research, 8(12): 388-393

[18] Rayner, J. C. W. and Best, D. J. (2013). Extended ANOVA and Rank transform procedures. Australian and New Zealand Journal of Statistics. Aust. N. Z.. J. stat. 55(3), $305-$ 319. Doi: 10.1111/anzs.12041.

[19] Sawlowsky, S. S., Bair, C. R. and Higgins, J. J. (1989). An investigation of the type I error and power properties of the
Rank transformation procedure in Factorial ANOVA. Journal of Education Statistics. Vol. 14 No. 3. Pp 255 - 267. Doi: $10.2307 / 1165018$.

[20] Thompson, G. L. (1991). A note on the rank transform for interactions. Biometrika. Vol. 78. (3). Pp. 697 - 701. Doi: 10.1093/biomet/78.3.697.

[21] Thompson, G. L. and Ammann, L. p. (1989). Efficacies of Rank transform statistics in two way models with no interaction. Journal of the American Association. Vol. 84. (405). 325 - 330. Doi: 10.1080/01621459.1989.10478773. 